\title{
AN ANTIGENIC PEPTIDE OF MYOSIN HEAVY CHAIN-LIKE PROTEIN FROM TRICHINELLA SPIRALIS
}

\author{
TAKUMI NAKADA, ISAO NAGANO, ZHILIANG WU AND YUZO TAKAHASHI \\ Received October 23, 2001/Accepted February 26, 2002
}

\begin{abstract}
We produced antigenic peptide of Trichinella spiralis newborn larvae (NBL) which seemed to be a part (approximately one fourth) of myosin heavy chain, and some basic profiles were revealed. The cDNA library was constructed from NBL and immunoscreened with an antibody against the parasite. A clone, designated NBL21, was selected. It contained a cDNA transcript of $1656 \mathrm{bp}$ in length, which encoded 552-amino acids (64868 Da in the estimated molecular weight). The fusion protein encoded by the clone NBL21 was produced in an Escherichia coli expression system and affinity purified. NBL21 fusion proteins migrated at $64 \mathrm{kDa}$ and reacted to T. spiralisinfected mouse sera and the antibody against NBL crude antigen. Antisera were developed against NBL21 fusion proteins, which reacted to a single band migrating at $200 \mathrm{kDa}$ on Western blotting analysis of crude extracts from muscle larvae, and reacted to hypodermal muscles of T. spiralis on immunohistochemical staining. The antigen was recognized by the mouse serum obtained from the early phase of infection, but the antigenicity was devoid of species specificity.
\end{abstract}

Key words: Myosin heavy chain, Trichinella spiralis, Antigen, Fusion protein

\section{INTRODUCTION}

Trichinella spiralis is a parasitic nematode that infects the skeletal muscle cells of mammals. Many questions remain to be answered about this parasite. Examples include how they evade host immune attack, and how they can establish parasitism in the host muscle cell. Moreover, the vaccine against this parasite is still far from routine usage.

For progress towards these goals, fusion proteins of Trichinella have been produced with some success. Vayssier et al . (1999) produced a protein from T. britovi, named as Tb Hsp70, which is a kind of heat shock protein with a molecular weight of $70 \mathrm{kDa}$. Sun et al. (1994) produced a protein Ts39 FP which is a potentially valuable antigen for vaccine development. Lindh et al . (1998) produced fusion protein which has properties of a myogenic repressor, and Nagano et al. (2001a) produced fusion protein with serine protease inhibitor activity.

In this study we produced a part of myosin heavy chain-like protein, and revealed some basic profiles including amino acid sequence and antigenicity. This is the first report on antigenic peptide of Trichinella myosin heavy chain which may afford better understanding of this conservative protein in Trichinella related research.

\section{MATERIALS AND METHODS}

\section{Parasites}

T. spiralis (ISS 413) and Trichinella pseudospiralis (ISS 13) were maintained in mice through oral infection. Muscle larvae were obtained by a conventional digestion method (Despomier, 1975). Newborn larvae (NBL) of $T$. spiralis were obtained through incubation of five day old adults in minimum essential medium (MEM) $+10 \%$ fetal calf serum (FCS) + antibiotics $(100 \mu l$ of streptomycin and 100 unit of penicillin per $100 \mathrm{~m} l$ of MEM). The NBL were frozen and stored until use.

\section{Crude extracts and ES products}

Larvae of Trichinella at the muscle stage were isolated from mice at 2 months post infection using digestion method. Crude saline extracts of larvae and ES products were prepared by conventional methods (Wakelin et al., 1994; Wu et al ., 1998).

\section{Preparation of antisera}

Polyclonal antibodies against crude extracts of the NBL were collected from BALB/c mice injected subcutaneously with $30 \mu \mathrm{g}$ of the crude extracts and Freund's complete adjuvant followed by two booster injections of $15 \mu \mathrm{g}$ of the crude extracts mixed with Freund's incomplete adju- 
vant at 2-week intervals.

Infected sera of the parasites and polyclonal antibodies against ES products were prepared by conventional methods (Nagano et al ., 2001a, b).

\section{cDNA library construction}

Construction of a cDNA library from $T$. spiralis NBL was performed according to our previous method (Nagano et al ., 1999). In brief, frozen NBL were homogenized in an extraction buffer (Quickprep micro mRNA purification kit, Amersham Pharmacia Biotech, Tokyo Japan), and mRNA was isolated by affinity chromatography using oligo (dT) cellulose.

Synthesis of cDNA from the resulting mRNA was performed using a Timesaver cDNA synthesis kit (Amersham Pharmacia Biotech) as described by the manufacturer's instructions. Resulting cDNAs were ligated into the $\lambda \mathrm{ZAP}$ II vector (Stratagene, La Jolla, California USA). The ligates were packaged in Gigapack Gold III packaging extract (Stratagene).

\section{Immunoscreening}

E. coli XL1-Blue MRF' strain infected with the $\lambda$ ZAP II vector was cultured on the NZY agar plates for $4 \mathrm{hr}$ at 42 ${ }^{\circ} \mathrm{C}$. And nitrocellulose membrane infiltrated with isopropyl$\beta$-D-thiogalactopyranoside (IPTG) was overlaid for $4 \mathrm{hr}$ at $37^{\circ} \mathrm{C}$. After blocking with $5 \%$ skim milk in phosphate buffered saline (PBS) overnight at $4{ }^{\circ} \mathrm{C}$, the membrane was reacted with polyclonal antibodies (1/100 diluted) against $T$. spiralis NBL. Goat anti-mouse IgG alkaline phosphatase conjugate was then used as the second antibody, and the membrane was incubated in 5-bromo-4-chloro-3-indolyl-ptoluidine salt (BCIP) and nitroblue tetrazolium (NBT) for development. The positive 66 clones were picked up and rescreened three times.

\section{DNA sequence and homology search}

The clone NBL21 was subjected to sequencing in which the Thermo Sequenase Cycle Sequencing Kit (Amersham) with bi-directional sequencing protocol and IRD-800 and IRD-700 labeled primers were used. The products were sequenced using an automatic sequencer (Model LIC-4200 L, Aloka, Tokyo Japan). The DNA sequences were assembled and analysed by using DNASIS software (Hitachi Software Engineering, Tokyo Japan). The NCBI BLAST network service at the National Center for Biotechnology Information was used to search for the sequence homology.

\section{Production of fusion protein}

The NBL21 clone was subcloned into the expression vector (pTrc His, Invitrogen, California USA) and trans- fected to E. coli (DH5 $\alpha$, Toyobo CO. LTD., Tokyo Japan) according to the manufacture's instructions. Transformants were grown in bacterial culture medium at $37^{\circ} \mathrm{C}$. To facilitate protein production, IPTG was added to give a final concentration of $1 \mathrm{mM}$, and cells were incubated for $3 \mathrm{hr}$ at $37^{\circ} \mathrm{C}$. The induced cells were fractured by ultrasound in 20 $\mathrm{mM}$ Tris $\mathrm{HCl}$ buffer ( $\mathrm{pH} 8.0$ ). The resultants were precipitated and the pellet was lysed by lysis buffer (20 mM Tris$\mathrm{HCl}, 0.5 \mathrm{M} \mathrm{NaCl}, 5 \mathrm{mM}$ imidazole, $6 \mathrm{M}$ guanidine hydrochloride). The fusion protein was affinity purified using a HisTrap kit (Amersham Pharmacia Biotech) as described by the manufacturer.

\section{Production of antibodies against the fusion protein}

To produce antibodies against the fusion protein NBL $21, \mathrm{BALB} / \mathrm{c}$ mice were injected subcutaneously with $30 \mu \mathrm{g}$ of the fusion protein and Freund's complete adjuvant. In order to boost the antibodies, after two weeks, the mice were injected with $15 \mu \mathrm{g}$ of the protein in Freund's incomplete adjuvant, and after another one week, $10 \mu \mathrm{g}$ of the protein was injected into the abdominal cavity. The mice were bled one week after the final booster.

\section{Immunocytochemistry}

Infected muscles of 42-day post infection were fixed with $4 \%$ paraformaldehyde and embedded in OCT compound (Miles Inc., Elkhart, Indiana USA) and frozen. Cryostat sections ( $4 \mu \mathrm{m}$ in thickness) were transferred to albumin coated microscope slides. The sections were immunostained using Histostain SP kit (Zymed Laboratories Inc., San Francisco, California USA) as described by the manufacturer's instructions. Briefly, the sections were treated with the first antibodies $(\times 100$ diluted antibody against the NBL21 fusion protein or control normal mouse serum) for $30 \mathrm{~min}$ at room temperature. After washing, the sections were treated with the biotinylated second antibody (Zymed Laboratories Inc.) for $30 \mathrm{~min}$ at room temperature, washed three times, treated with avidin coupled with peroxdase (Zymed Laboratories Inc.) for $10 \mathrm{~min}$ at room temperature, and reacted with diaminobendizone solution (Zymed Laboratories Inc.) for peroxidase staining.

\section{Antigenicity analysis of the fusion protein NBL21}

The fusion protein NBL21 was subjected to sodium dodecyl sulfate polyacrylamide gel electrophoresis (SDSPAGE) and blotted to nitrocellulose membranes. Membranes were blocked with skim milk and reacted with the first antibodies ( $\times 100$ diluted) including anti NBL antibodies, infected sera, antibodies against excretory and secretory (ES) products of muscle larvae, and control sera for $60 \mathrm{~min}$ utes at $37^{\circ} \mathrm{C}$. After washing, the membranes were treated 
with alkaline phosphatase-conjugated anti-mouse IgG for $30 \mathrm{~min}$ at $37^{\circ} \mathrm{C}$. The alkaline phosphatase was developed by using BCIP and NBT.

Specificity analysis of antibody against the fusion protein NBL21

Reactivity of anti-NBL21 fusion protein antibody was checked against 4 kinds of antigens including crude antigens and ES products from the two species (T. spiralis and T. pseudospiralis). The antigens were subjected to SDSPAGE and reacted to the anti NBL21 antibodies $(\times 100$ diluted) for $60 \mathrm{~min}$ at $37^{\circ} \mathrm{C}$. The nitrocellulose membranes were treated in the same way as described above.

\section{Specificity of fusion protein NBL21}

Antigen specificity of the fusion protein was assessed in two ways. The panel of crude antigens of parasites (Dirofilaria immitis, Ascaris lumbricoides, Toxocara canis, Gnathostoma nipponicum, Sparganum mansoni, Clonorchis sinensis, Anisakis simplex, Strongyloides stercoralis, Paragonimus westermani, Paragonimus miyazakii, Fasciola hepatica and Cysticercus cellulosae) was subjected to reaction against anti fusion protein NBL21 antibody by multiple dot ELISA according to the established method. The other method included ELISA where fusion protein NBL21 was reacted against a panel of human patient sera (trichinosis, paragonimiasis, dirofilariasis, dihyllobothriasis, anisakiasis, cysticercosis cellulose hominis, trichuriasis, gnathostomiasis and fasciolasis) according to the established method.

Kinetics of antibody response against the fusion protein NBL21

Three BALB/c mice were each inoculated orally with 300 infective larvae. Sera from infected mice were collected before inoculation for a control and at 1, 2, 3, 4, 6, 8 and 10 weeks after inoculation. Antibody titer against fusion protein NBL21 was assessed by means of ELISA according to the established method.

\section{Nucleotide sequence accession number}

The nucleotide sequence reported in this article has been submitted to the GenBank database and has the accession number AY033438.

\section{RESULTS}

\section{DNA and amino acid sequences}

The cDNA library from NBL gave 66 positive clones, which comprised of 3 groups of clones. One clone, designated NBL21, from the major group was further subcloned. The clone NBL21 consisted of 1656 bp nucleotide and en- coded 552 amino acid residues (Fig. 1). A homology study from NCBI BLAST search revealed significant homology with myosin heavy chain of some nematodes including Caenorhabditis elegans (GenBank under accession number X08067), Onchocerca volvulus (GenBank under accession number M74066) and Brugia malayi (GenBank under accession number L01625).

Myosin heavy chain of $C$. elegans had $65 \%$ homology in the DNA sequence and $66 \%$ in the deduced amino acid sequence. Myosin heavy chain of $O$. volvulus had $64 \%$ homology in the DNA sequence and $63 \%$ in the deduced amino acid sequence. Myosin heavy chain of $B$. malayi had $62 \%$ homology in the DNA sequence and $64 \%$ in the deduced amino acid sequence. In some areas such as amino acid sequence 260-293 (box in Fig. 1), more significant homology was found; $75-77 \%$ homology in the DNA sequence and $88-94 \%$ in the deduced amino acid sequence.

\section{Western blotting}

The fusion protein NBL21, produced by means of an $E$. coli expression system, was migrated at $68 \mathrm{kDa}$ on SDSPAGE and positively immunostained with anti $T$. spiralis NBL antibody (arrow in lane 1 of Fig. 2), T. spiralis infected sera (arrow in lane 2 of Fig. 2), T. pseudospiralis infected sera (arrow in lane 3 of Fig. 2), but not with anti ES product of $T$. spiralis muscle larvae (lane 4 in Fig. 2), anti ES product of T. pseudospiralis muscle larvae (lane 5 in Fig. 2) nor with control sera (figure not shown).

An SDS-PAGE analysis revealed that crude antigens and ES product of muscle larvae were composed of many bands with different molecular weights. Out of many bands, only one band of $200 \mathrm{kDa}$ (corresponding to the expected size) of crude antigens of T. spiralis (lane 2 in Fig. 3) and $T$. pseudospiralis (lane 4 in Fig. 3) were positive by immunostaining with the antibody against NBL21 fusion protein. No bands of the ES product of the two species were positive by the immunostaining (lane 3, 5 in Fig. 3).

\section{Immunolocalization}

As shown in Fig. 4 A, strong positive immunostaining was observed in the internal structures of the muscle larvae. The staining consisted of a spotty pattern and lining beneath the cuticle surface, and internal organs were negative by the staining. The control sera failed to stain any structures (Fig. 4 B).

\section{Antigen specificity}

The multiple dot ELISA showed reactivity of the antibody against the fusion protein NBL21 against crude extracts of D. immitis, A. lumbricoides, T. canis, G. nipponicum, S. mansoni, C. sinensis but not against A. simplex, $S$. 
NBL21 1 :LNRLXPQYQTQLEEAKRTADEEKNERHNLAAQLKNMEHENQSLREQLEEEAESKTEMQRH ISKLNAEIQ0 C. ele 1314:. H. . KSTL. S. . D. TR. NY. . SR. . QA . . TA. . L. . . TI . . H. D. . . . . ADLT. Q . . . . . . . . 0. vol 1308:MT. . KA. LTS. . . . R. SL. . ARD. N. . . . M. . YQ. . IEQVL. SM. . I I. GIS. LMKQL. RA. . . . . B. mal $664:$ MT. . KA. LTS. .... R. SL. . ARD. N. .... S. . YQ. . IEQI. . SM. . . I. A. N. LMKQL. RA. . . . . $\begin{array}{lllllllllllll}* * & * * & * & * & * * * & * & * * * & * * & * * & * & * * * & * & * * * * * *\end{array}$

NBL21 71:WKAKFESEGLARVDE I EEAKRKLTQKVQEMQEAFEAANGKIASLEKIRHKLLGE IDDAQVDVERANNYAA C. ele 1384 . . . R. D. . . NKLE. . A. . KA. QL. . . LTDTN. GLFA. . . Q . . V. F. . MQDL. . . . . . . K. AAQV. 0. vol 1378:. QTR. . . . . LKG. . L. . S. KRQMH. MN. L. . TLD. . S. . S. . . TKSR. VSDL. . . M. . . . . S. . S B. mal 734:. QTR. ..... LKS. . L. . S. KRQM. . IN. L. . LD. . S. . S. . . TKSR. VSDL. . . M. . . . . S. . S $* \quad * * * * * \quad * * \quad * \quad * \quad * \quad * * * * * \quad * \quad * * * * * * * *$

NBL21 141 :QLEKKOKGFDK IVDEWKKKCDDLSSELDASQRENRHLSTECFKLKNSQDEL I EQ I EAVRRENKNLVQE IK C. ele 1454:FY. . HRRQ. ES. IA . . . . T . . . . . . A. . D. . . . . DL. . A. TAN. . A. YLDST . . . S. A. . V. 0 . vol $1448: \ldots \ldots$. . . VI . . . . T. . IAT. V. NA. . A. NV. . L. . . SE. . VL. T. . GL. . . . E. A. . R. B. mal $804:$ L. . . . . . . . VI. ... R. T. . ILA. V. NA. . A. NV. . L. . . SER. . VL. T. . GL. . . . E. A. . .

NBL21 211:DITDQLGEGGRSVHELOKVVRRLELEKEELQQALDEAESALEAEESKVMRAOVEVSQ IRQE I EKR IREKE

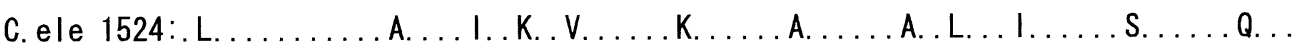

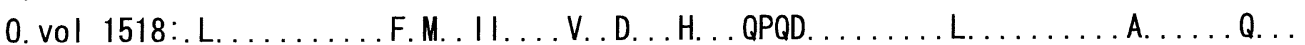

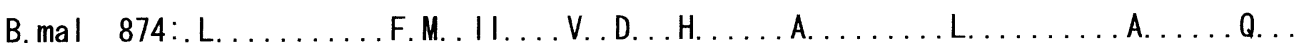

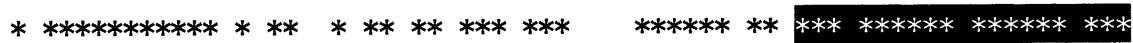

NBL21 281 :EEFENTRKNHQRALDSMQATLESEAKGRAEALRLKKKLESD INELE I ALDHANKANADAQKNIKMYQDQV C. ele $1594: \ldots$. . R . . . E. . . . . A. T. QKE. . . I . . . . . . D. . . . . . R. Y. . . . T. . K. MET.

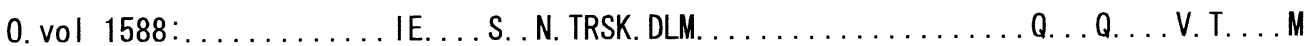
B. mal $944: \ldots \ldots \ldots \ldots$ IE. . . S. . N. TRSK. DLM. . . . . . F . . . . . Q . EV. . V. R. . I $* * * * * * * * * * * * \quad * * * * * * * \quad * * * * * * * * * \quad * * * * * * * * * * * * * * * *$

NBL21 351 :KELQMHIEDEQROREE IREOFHASEKRCAMLQSEKEEYMTASEQAERARRQAEAELYELREQVNELSSTN C. ele 1664:Q . . FQ. . E. . . KD . . . . L. . . . N. I . . . D. LAQQA. A . . . . N . . . CI . . . N. D. NAHV O. vol 1658:R. . QQV. T. . NGRNS. . YLNM. . KATL. ..... MSV. NG. .... K. . DYDAN. AHT. C . . . AQA B. mal 1014:R. . QQV. I . . N. . . . . . YLNM. . KATL. . . . . TSV. MD. . . T. K. S. RDAN. AHV. C. . . AQA *** **** **** ** ****** $*$ ***

NBL21 421: ASLSA IKRKLEGELQALHAELDDTLNELKKVDEQCKKAMTDAARLAEELROEQEHSMHVERMRKGLEQQV

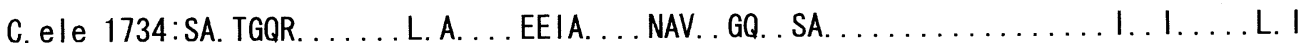
0. vol 1728:E. . CGSR. . DT. . L. IQ. D. E. . . Y. ASE. R. . A. SS . . . . . Q. . K. . N. LQND. I. . A. . S. L B. mal 1084:E. . SV. K. . T. . L. IQ. D. E. . . Y. ASE. RY. A. SS . . . . . Q . . . . N. LQND. I. . A. . S. L

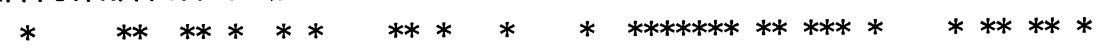

NBL21 491 :KEMOVRLDEAEQAALKGGKK I I QKLEQR IRELEQELDLEQRRHQETDKNMRKQDRR IKETDS C. ele $1804: \ldots$. . . D. . N. . . . . . . AQ . A. . Al . . . G. . . . D. E. . W. . AE. . V. . VEF 0. vol 1798 . . . A. . . . VL. . . . N. D. A. . S. . . . S. . G. . . Y. . N. SLT. HE. . R. LQF B. mal $1154: \ldots$ A. . . . A. . . . . . V. A. . S. . . . S. . G. R. .Y. . N. SLT. HE. . R. LQF $* * * * * * * * * \quad * * * * * * * \quad * * * * * \quad * * * * * * * * * * \quad * \quad * * \quad *$

Figure 1 Comparison of a deduced amino acid sequence of the clone NBL21 and its comparable genes from other nematodes including $C$. elegans (C. ele; amino acid residues 1314-1865 in the total 1969 residures), O. volvulus (O. vol; amino acid residues 1308-1859 in the total 1957 residues), B. malayi (B. mal; amino acid residues 664-1215 in the total 1313 residues). The asterisks indicate nucleotides, which are identical to those of C. ele, O. vol, B. mal and NBL21. A box shows high homology region mentioned in the text. 


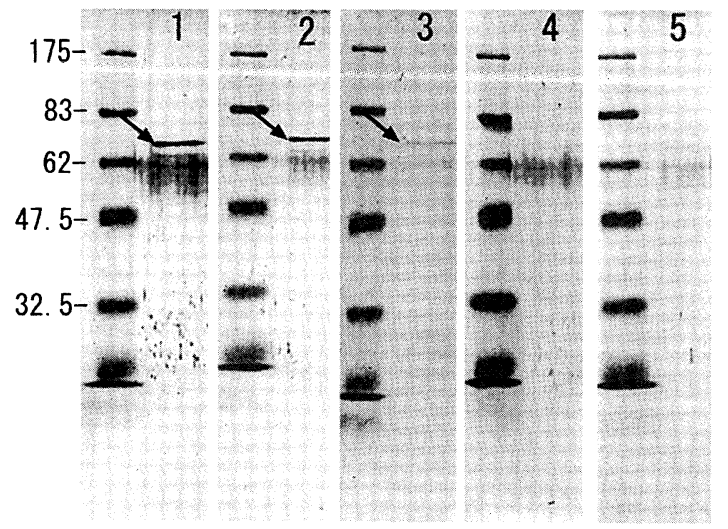

Figure 2 Western blots analysis of the fusion protein NBL21. E. coli expressed NBL21 fusion protein was reacted with anti NBL21 antibody (lane 1), infected sera of T. spiralis (lane 2), infected sera of T. pseudospiralis (lane 3), anti ES product of T. spiralis antibody (lane 4) and anti ES product of T. pseudospiralis antibody (lane 5). The left side of each lane is molecular marker and the right side is the test sample. The numbers of the left side is molecular weight. The arrow shows positive band.

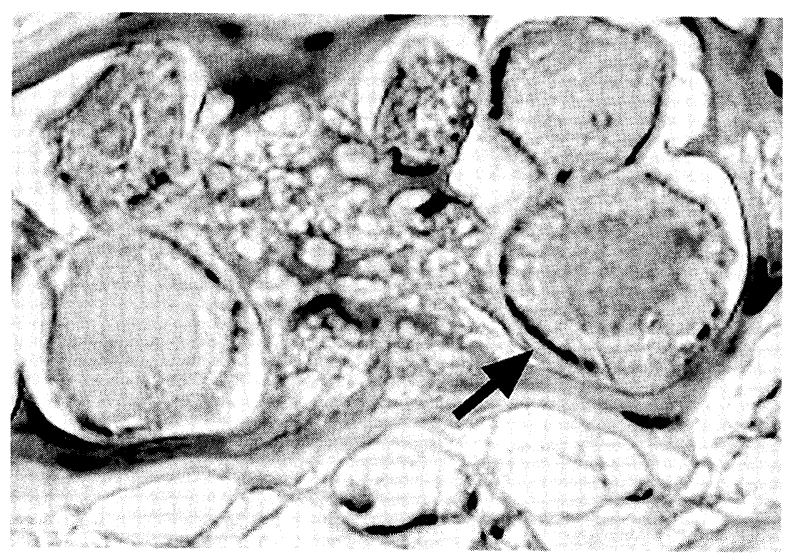

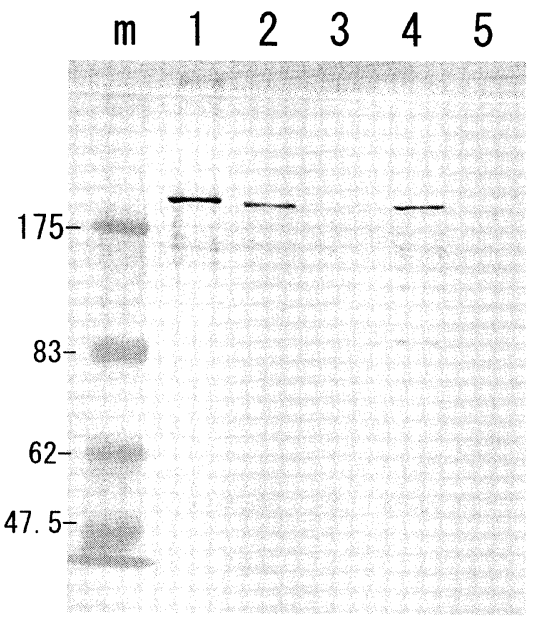

Figure 3 Western blot analysis of reactivity of anti NBL21. The mouse antibody produced against the fusion protein NBL 21 was reacted with NBL crude antigen (lane 1), T. spiralis crude antigen (lane 2), $T$. pseudospiralis crude antigen (lane 4), ES products of T. spiralis (lane 3) and ES products of T. pseudospiralis (lane 5). The numbers are molecular weights of marker $(\mathrm{m})$.

Figure 4 Immunocytochemical staining of muscle larvae of T. spiralis with antibody against NBL 21 fusion protein (A) and control serum (B). The arrow shows the positive staining.

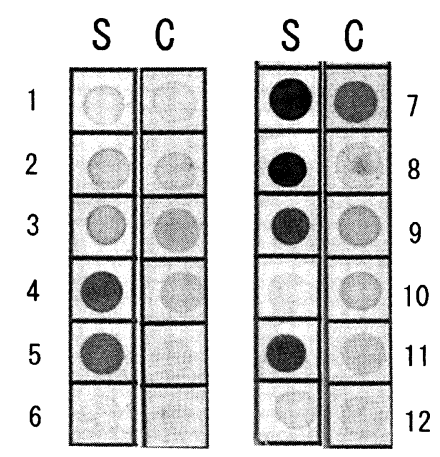

Figure 5 Dot - ELISA analysis of reactivity of anti NBL21 fusion protein antibody $(\mathrm{S})$ and normal mouse sera (C) against a panel of crude antigens. 1. P. westermani, 2. P. miyazakii, 3. F. hepatica, 4. C. sinensis, 5. S. mansoni, 6. C. cellulosae, 7. D. immitis, 8. T. canis, 9. A. lumbricoides, 10. A. simplex, 11. G. nipponicum, 12. S. stercoralis. Crude antigens from C. cellulosae, A. simplex and S. stercoralis gave negative results which may suggest major difference in antigenic epitope of myosin heavy chain from other parasites. 
stercoralis, P. westermani, P. miyazakii, F. hepatica and $C$. cellulosae. D. immitis and T. canis especially exhibited strong reactivity ("S" in Fig. 5). Normal mouse sera (" $C$ " in Fig. 5) gave negative or weak positive result.

The fusion protein reacted positive for ELISA against sera from all patients examined including nematode, cestoide and trematode infection (figures not shown).

\section{Antibody response kinetics}

Antibodies against the fusion protein were detected from 4 weeks after the infection and reached a maximum at 8 weeks, and the ELISA titer remained high throughout the 10-week-long experiment (figures not shown).

\section{DISCUSSION}

Recent progress in cell biology has enabled us to produce a large amount of proteins with high purity. Taking advantage of this methodology, proteins of a parasite origin have been mass-produced for a variety of usages including immunodiagnostic antigen (Chung and Ko, 1999) and vaccine (Sun et al ., 1994; Prema et al ., 1994). Genes encoding specific antigens of ES products $(43,39$ and $53 \mathrm{kDa})$ have been characterized (Sugane and Matsuura, 1990; Zarlenga and Gamble, 1990; Su et al ., 1991; Vassilatis et al ., 1992).

In this study we obtained the clone NBL21 from $T$. spiralis NBL. This clone is likely a part of the myosin heavy chain from the sequence homology and in situ localization of this protein within the parasite. This study also revealed some basic profiles of the myosin heavy chain including the DNA and amino acid sequence which is discussed with comparable genes of other nematodes such as $C$. elegans, B. malayi and $O$. volvulus. Antigenic specificity and possible immunodiagnostic usages were also assessed.

Myosin is a fundamental protein shared by all kinds of cells. The DNA sequence of such a protein should be highly conservative. This notion is supported by the present study which showed high homology among other nematodes. In particular, some areas of the nucleotides are significantly conserved. Such area may be responsible for its common function as myosin.

The peptide NBL21 seems to carry immunodominant antigen which is recognized by hosts during the experimental infection. A similar result was reported by $\mathrm{Li}$ et al. (1995) who demonstrated that myosin heavy chain carries immunodominat filarial antigen. The clone NBL21 had $48 \%$ homology with the myosin heavy chain of hosts (humans and mouse), unshared sequence may explain the reasons why the fusion protein NBL21 is highly antigenic against the hosts.

We have no ready explanation as to how this internal antigen is exposed to the host immune system. Interestingly, paramyosin, which is also an internal constituent of parasites, carries immunodominant antigen which may be used as a protective antigen against schistosome infection (Xu et al., 1989). Our preliminary experiment, however, showed that the fusion protein NBL21 does not provoke protective immunity against challenge infection.

Fusion proteins of parasites can be a candidate for immunodiagnostic antigen as suggested by many authors (Zarlenga and Gamble, 1990; Chandrashekar et al ., 1991; Zarlenga et al., 1994). The mice infected with Trichinella seem to provoke antibodies at detectable levels against the fusion protein NBL21 from the early phase of the infection, therefore, the antigen of the fusion protein NBL21 seems to be Group I antigen (Denkers et al., 1990) and rapid responding group antigen (Takahashi et al ., 1990). One drawback of this fusion protein is its lack of species specificity. The antibody against the fusion protein NBL21 reacted against sera from a variety of parasite crude antigens. Therefore, this fusion protein can be used for early diagnosis of some parasite infection.

\section{ACKNOWLEDGEMENTS}

This study was partially supported by grants from the Ministry of Education, Science and Culture (12670229). The authors are thankful to Prof. Y. Nawa, Miyazaki Medical College, who kindly provided a panel of parasite antigens.

\section{REFERENCES}

1) Chandrashekar, R., Masood, K., Alvarez R.M., Ogunrinade, A.F., Lujan, R., Richards, F.O. and Weil, G.J. (1991): Molecular cloning and characterization of recombinant parasite antigens for immunodiagnosis of onchocerciasis. J. Clin. Invest., 88, 1460-1466

2) Chung, Y.Y.Y. and Ko, R.C. (1999): A novel cDNA clone encording a specific excretory/secretory antigen of larval Trichinella pseudospiralis. Parasitol. Res., 85, 685-691

3) Denkers, E.Y., Wassom, D.L., Krco, C.J. and Hayes, C.E. (1990): The mouse antibody response to Trichinella spiralis defines a single, immunodominant epitope shared by multiple antigens. J. Immunol., 144, 3152-3159

4) Despomier, D.D. (1975): Adaptive changes in muscle fibers infected with Trichinella spiralis. Am. J. Pathol., 78, 477-496

5) Li, B.W., Hoppe, P.E. and Weil, G.J. (1995): Cloning of an early immunodominant filarial antigen: a member of the Brugia malayi myosin heavy chain gene family. Int. J. Parasitol., 25, 611-619

6) Lindh, J.G., Connolly, B., McGhie, D.L. and Smith, D.F. (1998): Identification of a developmentally regulated Tri- 
chinella spiralis protein that inhibits MyoD-specific protein: DNA complexes in vitro. Mol. Biochem. Parasitol., 92, 163-175

7) Nagano, I., Wu, Z., Matsuo, A., Pozio, E. and Takahashi, Y. (1999): Identification of Trichinella isolates by polymerase chain reaction-restriction fragment length polymorphism of the mitochondrial cytochrome C-oxidase subunit I gene. Int. J. Parasitol., 29, 1113-1120

8) Nagano, I., Wu, Z., Nakada, T., Matsuo, A. and Takahashi, Y. (2001a): Molecular cloning and characterization of a serine proteinase inhibitor from Trichinella spiralis. Parasitol., 123, 77-83

9) Nagano, I., Wu, Z., Nakada, T., Matsuo, A. and Takahashi, Y. (2001b): Molecular cloning and characterization of a 21 $\mathrm{kDa}$ protein secreted from Trichinella pseudospiralis. J. Helminthol., 75, 273-278

10) Prema, A., Lauri, A.E., Raul, I., Florencio, M.U. and Judith, A.A. (1994): Molecular analysis of antigens targeted by protective antibodies in rapid expulsion of Trichinella spiralis. Mol. Biochem. Parasitol., 65, 201-211

11) Su, X., Prestwood, A.K. and McGraw, R.A. (1991): Cloning and expression of complementary DNA encoding an antigen of Trichinella spiralis. Mol. Biochem. Parasitol., $45,331-336$

12) Sugane, K. and Matsuura, T. (1990): Molecular analysis of the gene encoding an antigenic polypeptide of Trichinella spirasis infective larvae. J. Helminthol., 64, 1-8

13) Sun, S., Xu, W., He, N. and Sugane, K. (1994): An antigenic recombinant fusion protein from Trichinella spiralis induces a protective response in $\mathrm{BALB} / \mathrm{c}$ mice. $\mathrm{J}$. Helminthol., 68, 89-91

14) Takahashi, Y., Mizuno, N., Uno, T., Aisaka, A. and Araki T (1990): A spectrum of antibody response with time after Trichinella spiralis infection in rats. J. Parasitol., 76, 230239
15) Vassilatis, D.K., Despommier, D.D., Misek, D.E., Polvere, R.I., Gold, A.M. and Poleg, L.H.T. van der (1992): Analysis of a $43 \mathrm{kDa}$ grycoprotein from the intracellular parasitic nematode Trichinella spiralis. J. Biol. Chem., 267, 18459-18465

16) Vayssier, M., Le Guerhier, F., Fabien, J.F., Philippe, H., Vallet, C., Ortega-Pierres, G., Soule, C., Perret, C., Liu, M., Vega-Lopez, M. and Boireau, P. (1999): Cloning and analysis of a Trichinella britovi gene encoding a cytoplasmic heat shock protein of $72 \mathrm{kDa}$. Parasitol., 119, 81-93

17) Wakelin, D., Goyal, P.K., Dehlawi, M.S. and Hermanek, J. (1994): Immune responses to Trichinella spiralis and $T$. pseudospiralis in mice. Immunol. 81, 475-479

18) Wu, Z., Nagano, I. and Takahashi, Y. (1998): Differences and similarities between Trichinella spiralis and T. pseudospiralis in morphology of stichocyte granules, peptide maps of excretory and secretory (E-S) products and messenger RNA of stichosomal glycoproteins. Parasitol., 116, 61-66

19) Xu, H., Miller, S., van Keulen, H., Wawrzynski, M. R., Rekosh, D.M. and LoVerde, P. T. (1989): Schistosoma mansoni tropomyosin: cDNA characterization, sequence, expression, and gene product localization. Exp. Parasitol., $69,373-392$

20) Zarlenga, D.S. and Gamble, H.R. (1990): Molecular cloning and expression of an immunodominant $53-\mathrm{kDa}$ excretory-secretory antigen from Trichinella spiralis muscle larvae. Mol. Biochem. Parasitol. 42, 165-174

21) Zarlenga, D.S., Rhoads, M.L. and al-Yaman, F.M. (1994): A Taenia crassiceps cDNA sequence encoding a putative immunodiagnostic antigen for bovine cysticercosis. Mol. Biochem. Parasitol., 67, 215-223 